\title{
Pia Nykänen
}

\section{"Critical appraisal", riktlinjer och praktikerns dilemma}

\section{Critical appraisal, guidelines and the practitioner's dilemma}

In 2008 a Swedish governmental report pointed out that the social services increasingly need to conduct their work based on an understanding of the effects of their services. The report stressed the development of an evidence-based practice as the long-term objective. However, the Swedish social services have been relatively slow to implement EBP. Several reasons can be given for this, including lack of contact between national, regional and local levels and tensions between state authorities, researchers and professionals regarding if and how EBP should be pursued in practice. The aim of this article is twofold; to identify and evaluate arguments for and against the critical appraisal approach and the guidelines approach with respect to how EBP ought to be conducted in the social services, and secondly, to suggest characteristics that other versions should have in order to try to avoid some of the counter-arguments that the two former approaches face. The examination of arguments shows that some arguments can be directed against both approaches and that some arguments are in need of empirical support. A hypothetical and a "practical" dilemma for the practitioner is presented. The first arises when a hypothetical practitioner agrees with counter-arguments against the two approaches when it comes to the question of who should appraise evidence. The second might arise in today's practical context in terms of the practitioner facing a "contradictory environment". Finally, "stability and continuity", "sufficient proximity" and "multi-disciplinarity" are suggested as desirable characteristics of other versions of EBP organizing.

Pia Nykänen är FD i praktisk filosofi och lektor i utbildningsvetenskap vid Institutionen för pedagogik, kommunikation och lärande vid Göteborgs universitet.

Kontakt:pia.nykanen@gu.se 


\section{Inledning}

Det finns två syften med den här texten. Det första är att försöka bidra med att problematisera argumenten för respektive emot två hållningar - critical appraisal och riktlinjemodellen - som förekommer i diskussionen kring införandet av en evidensbaserad praktik i socialt arbete. ${ }^{1}$ Det andra syftet är att mot bakgrund av vissa av motargumenten mot de båda modellerna försöka identifiera några karakteristika som andra föreslagna versioner skulle kunna behöva ha för att undgå samma kritik. ${ }^{2}$

Upplägget ser ut på följande vis: först ges en kort bakgrund till tankarna om evidensbaserad praktik inom socialtjänsten. Sedan beskrivs de två modellerna översiktligt. Därefter redogörs för argument hämtade från forskningslitteratur (och annan relevant litteratur) för respektive emot de två. Argumenten värderas och vissa premisser granskas närmare. Därefter presenteras praktikerns dilemma, en svårighet som presenteras dels i ett hypotetiskt exempel, dels som en reell svårighet som kan möta den verksamme praktikern i vardagen.

Slutligen ställs frågan om det finns något att lära av motargumenten mot de två EBP-modellerna. Mot bakgrund av några av de argument som förts fram, går det att utveckla andra versioner att organisera EBP-arbetet på? Finns det några drag eller kännetecken hos dem som skulle kunna motiveras? Tre karakteristika förs tentativt fram som förslag.

Evidensbaserad praktik inom socialtjänsten har förtjänstfullt beskrivits och undersökts av forskare, främst inom socialt arbete, med avseende på många olika aspekter. Här anger jag endast några exempel, schematiskt ordnade: EBP:s historia och bakgrund inom den evidensbaserade medicinen (Bergmark, Bergmark \& Lundström, 2011; Svanevie, 2011), EBP i relation till olika styrningsideal (Liljegren \& Parding, 2010; Rexvid, 2016), implementering av EBP (Denvall \& Johansson, 2012; Ponnert \& Svensson, 2011; Svanevie, 2011), standardisering inom EBP (Björk, 2016; Martinell Barfoed, 2014), socialarbetares förståelse av EBP (Avby, Nilsen \& Abrandt Dahlgren, 2014; Odhnoff, 2016). Samtliga aspekter - och säkerligen ytterligare andra - är viktiga för att belysa fenomenet EBP. Anspråken $\mathrm{i}$ artikelns tidigare delar är något andra: att belysa och granska argumentation som förs fram om olika sätt att bedriva EBP på. I artikelns avslutande del behandlas några av motargumenten mot de båda modellerna som hjälpmedel i att försöka hitta konstruktiva karakteristika för andra EBP-

1 Socialt arbete, det sociala arbetet och socialtjänsten används i texten synonymt även om socialt arbete kan utföras utanför socialtjänsten. Om den akademiska disciplinen socialt arbete avses, framgår det av texten i övrigt.

2 Med modell avses här ett visst sätt att arbeta på (vilket inte utesluter en förståelse av arbetssätten som "process"). Då ordet riktlinjemodell också redan använts av svenska forskare inom socialt arbete, väljer jag att anamma den beteckningen. 
versioner. Här används tidigare förslag från forskare inom socialt arbete som avstamp för de karakteristika som läggs fram.

Två texter som är viktiga för artikeln är författade av Statskontoret. Statskontoret är regeringens utrednings- och utvärderingsmyndighet och de "utreder, utvärderar och följer upp verksamheter och myndigheter ur ett effektivitetsperspektiv" (Statskontoret, 2017). Dessa texter blir viktiga eftersom Statskontoret utvärderar EBP-arbetet som utförts och utförs av centrala myndigheter inom området. Dock utreds, utvärderas och uppföljs myndigheter ur ett effektivitetsperspektiv och Statskontorets texter ska alltså betraktas mot denna uppdragsbakgrund.

\section{Bakgrund $^{3}$}

Kommittédirektivet Nya former för stöd till kunskapsutvecklingen inom socialtjänsten (Dir. 2007:91) får tjäna som utgångspunkt för en kort bakgrundsbeskrivning. Där sägs att "[k]unskapsbasen för insatserna inom socialtjänsten är outvecklad" och det tillsammans med brukares behov av att ha kunskap om "vad som fungerar bra", medborgares behov av information och de professionellas möjligheter till att kunna utveckla sin verksamhet välgrundat bidrog med skäl för en utredning (Dir. 2007:91 i SOU 2008:18, s. 127f.). ${ }^{4}$ Utredningen resulterade i betänkandet Evidensbaserad praktik inom socialtjänsten - till nytta för brukaren (SOU 2008:18). I betänkandet anförs att socialtjänsten i ökad utsträckning behöver bedriva insatser utifrån kunskaper om effekterna av dem och utredaren framhåller att utveckla en evidensbaserad praktik som det långsiktiga målet (SOU 2008:18, s. 9f.).

Efter betänkandet följde en departementspromemoria och en överenskommelse mellan staten och Sveriges Kommuner och Landsting (SKL) om en plattform för att kunna arbeta med att utveckla och stödja EBP inom socialtjänsten (Socialdepartementet, 2010). Överenskommelser har därefter gjorts kontinuerligt mellan parterna (Socialdepartementet, 2011;2012;2013;2014;2015;2016).

EBP omtalas 2010 som "ett förhållningssätt för ett ständigt och systematiskt lärande, där brukaren och de professionella, utifrån bästa tillgängliga kunskap, tillsammans fattar beslut om lämpliga insatser i den mån brukaren eller hans eller hennes närstående kan och vill vara delaktiga" (Socialdepartementet, 2010, s. 3). Men ytterligare andra förståelser av EBP återfinns genom åren, till exempel:

3 Bakgrunden följer till stor del bakgrundsbeskrivningen i Munthe, Nykänen och Sandman (2015), avsnitt 5.1, s. 33f. För en utförlig bakgrund, se t.ex. Svanevie (2011).

4 I den här texten används ordet brukare för servicemottagare i offentliga sektorn (se Dahlberg \& Vedung, s. 41f.). Ordet brukare ska här därför inte förstås som att det endast refererar till dem "som får individuellt behovsprövade insatser" (se Socialstyrelsen, 2013, där avgränsningen betonas). Detta för att inte genom termen göra skillnad mellan dem som får insatser genom behovsprövning och dem som på eget initiativ söker upp exempelvis en ungdomsmottagning för råd och stöd. 
en medveten och systematisk användning av: den bästa tillgängliga kunskapen; den professionelles expertis; den berörda personens situation, erfarenhet och önskemål. Hur informationen från de olika kunskapskällorna vägs samman bestäms av det nationella och lokala sammanhanget, till exempel lagstiftning, riktlinjer och tillgängliga insatser. (Socialstyrelsen, 2012a, s. 11)

Den evidensbaserade praktiken beskrivs även som "ett alternativ till en praktik där professionella bestämmer på egen hand, utan insyn och utan hänsyn till de senaste vetenskapliga rönen" (Socialstyrelsen, 2012b, s. 10). Brukarens preferenser och intressen beskrivs också som mycket betydelsefulla: "I EBP väger den hjälpbehövandes egna önskemål tungt (såvida inte lagstiftningen säger annat)" (Socialstyrelsen, 2012b, s. 8).

Vad EBP inte ska förstås som omtalas också och ett antal missuppfattningar anges: "att evidensbaserad praktik är detsamma som evidensbaserade metoder"; "att EBP ger entydiga besked för beslutsfattande"; "att EBP reducerar professionella till robotar"; "att endast randomiserade kontrollerade studier ger information om metoders effekter" och "att EBP handlar om att spara pengar" (Socialstyrelsen, 2012b, s. 17).

\section{Critical appraisal}

Den modell som brukar framhållas som den "ursprungliga" för EBP är den som av många benämns critical appraisal och som först presenterades av bland andra David L. Sackett i texter om evidensbaserad medicin (EBM). Critical appraisal-processens fem steg som praktikern ska följa, beskrivs av Sackett med flera på följande vis:

Step 1 converting the need for information (about prevention, diagnosis, prognosis, therapy, causation, etc.) into an answerable question.

Step 2 tracking down the best evidence with which to answer that question.

Step 3 critically appraising that evidence for its validity (closeness to the truth), impact (size of the effect), and applicability (usefulness in our clinical practice).

Step 4 integrating the critical appraisal with our clinical expertise and with our patient's unique biology, values and circumstances.

Step 5 evaluating our effectiveness and efficiency in executing steps $1-4$, and seeking ways to improve them both for next time (Sackett et al., 2000, s. 3f.). ${ }^{5}$

5 Den här versionen av de fem stegen skiljer sig från den först utarbetade från 1997 (se Sackett et al., 1997). Där nämndes inte patienten i steg 4 och följaktligen används versionen från 2000 hellre av dem som anför brukarargumentet för critical appraisal. 
Denna tidiga EBM-version kan jämföras med EBP-versioner som utarbetats för svensk socialtjänst, till exempel den som finns på Kunskapsguiden.se. Det praktikern ska göra är att

1. Omvandla information till en fråga som kan besvaras

2. Söka bästa tillgängliga kunskap för att besvara frågan

3. Värdera kunskapen utifrån tillförlitlighet och användbarhet

4. Väg samman kunskapskällorna med den egna professionella kompetensen, den

berörda individens problem, unika förutsättningar och önskemål

5. Följa upp de fyra föregående stegen och sträva efter att förbättra arbetet. (Kunskapsguiden.se, 2017)

\section{Riktlinjemodellen}

Vad är då riktlinjemodellen för hur EBP bör bedrivas? Så här beskrivs den av Bergmark, Bergmark och Lundström:

Den andra grundläggande modellen för att säkerställa att professionella faktiskt använder evidensbaserade interventioner kan ses som en reaktion på att Sacketts modell tycks vara svårgenomförbar. I stället för en självständig, kritiskt värderande praktiker framförs nödvändigheten av riktlinjer (guidelines) och andra typer av sammanställningar av forskning. Dessa kan presenteras för praktiker, som sedan tillämpar dem. (Bergmark, Bergmark \& Lundström, 2011, s. 16)

Bergmark och medförfattare hänvisar till Rosen och Proctor som exempel på forskare inom socialt arbete som verkar förorda en dylik modell och de senare anför främst "det orealistiska argumentet" som skäl för en modell mer baserad på riktlinjer:

We concur with the objectives and premises underlying EBP, but we believe that it places too heavy a burden on practitioners, exceeding their capacity to systematically process and judiciously integrate research results from disparate studies (or critical reviews) and to then apply those results to treatment decisions for individual clients. We think that in order to base decisions for individual clients on the best available evidence, practitioners must also be equipped with a means of organizing, synthesizing, and judiciously using empirically based probabilistic evidence to practice decisions. We view practice guidelines, as we conceive their function and structure $[\ldots]$ as a requisite tool for implementing evidence-based practice. (Rosen \& Proctor, 2003, s. 5) 
Vid en jämförelse med critical appraisal så verkar riktlinjemodellens alternativ bestå i ett annat svar på hur steg två och tre i critical appraisal ska förstås utifrån frågorna "Vem?" och "Hur?" Vem ska söka efter den bästa tillgängliga kunskapen, vem ska värdera den utifrån tillförlitlighet och användbarhet och på vilket sätt? Svaret från critical appraisal är oftast den enskilde praktikern eller de enskilda praktikerna. ${ }^{6}$ Riktlinjemodellen däremot verkar föreskriva att praktikern inte ska ägna sig åt steg tre, det vill säga, att själv värdera kunskapens tillförlitlighet och användbarhet. Det skulle vara lätt att tro att riktlinjemodellen också entydigt säger att praktikern inte heller ska ägna sig åt steg två, att söka efter den bästa tillgängliga kunskapen för att kunna besvara sin fråga, men det verkar vara en förhastad slutsats: praktikern är den som inleder processen med sitt sökande efter kunskap och letar sig då fram bland olika resurser.

De resurser som kan stå till buds för en svensk socialarbetare anges till exempel i Socialstyrelsens webbaserade EBP-utbildning. Följande listas som exempel på var praktikern kan söka kunskap: "Facktidskrifter (t.ex. Socionomen, Äldre i centrum), vetenskapliga tidskrifter, FoU, regionstöd etc., Publikationer från Socialstyrelsen (t.ex. nationella riktlinjer), Webbplatser (t.ex. Kunskapsguiden.se, Metodguiden.se, SBU. se), Lokala riktlinjer, Resultat från systematisk uppföljning, Forskningsrapporter" (Kunskapsguiden.se, 2017).

I den webbaserade EBP-utbildningen ges även vägledning om hur de olika källorna ska värderas. Här anges de fyra grader av tillförlitlighet hos vetenskapligt underlag som kan hänföras till det internationella evidensgraderingssystemet GRADE och som i Sverige används av exempelvis Socialstyrelsen och Statens beredning för medicinsk och social utvärdering (SBU). På Kunskapsguiden.se finns också en webbutbildning i GRADE vars mål är att "ge dig en introduktion till den process som Socialstyrelsen använder för att sammanställa forskning och värdera forskningsresultatens tillförlitlighet" (Kunskapsguiden.se, 2017).

6 Notera dock att inte ens Sackett och medförfattare förespråkar att praktikerna alltid ska göra detta själva. I vissa fall (med problem som praktikerna stöter på mer sällan) så föreslås att de ska söka efter kritiska bedömningar gjorda av andra som också samtidigt redovisat vilka kriterier de använt sig av i evidensbedömningen av forskningen och hur de kommit fram till sina slutsatser baserat på kriterierna. Då blir steg 3 inte aktuellt för praktikern och avgränsningarna för källorna i steg 2 blir alltså de som redan har bedömts kritiskt. Se Sackett et al. (2000), s. 4f., och Gibbs och Gambrill (2002), s. 455. Det kontrasterande mellan critical appraisal och riktlinjemodellen, som framförts i diskussionen, blir mot denna bakgrund något förvånande: källorna till critical appraisal (Sackett et al.) förespråkar inte själva en sådan sträng variant (vad gäller vem som ska utföra evidensvärdering) som de verkar ha tillskrivits. 


\section{Argument för respektive emot de två modellerna}

Det är värt att notera att de argument som framförs för respektive emot de två modellerna förhåller sig till varandra, det vill säga, de tar inte sällan formen av att den ena modellen är mer (eller mindre) av något (t.ex. tar mer hänsyn till brukares perspektiv) än den andra. Det är alltså ett slags "relativ argumentation" och det gäller särskilt ofta riktlinjemodellen som jämförs med den äldre critical appraisal. Några av de argument som framförts för critical appraisal har också förekommit i form av argument för EBP $i$ sig. Det gäller tidiga texter (av t.ex. Gambrill) då EBP presenterades som synonym med critical appraisal.

Argumenten förekommer inte i forskningslitteraturen med sådana beteckningar som de ges här. De har också renodlats för att göra dem tydligare och därmed mer möjliga att bemöta som argument. Listan över argument gör heller inte anspråk på att vara fullständig, fler kan gissningsvis finnas i litteraturen.

\section{Argument för och emot critical appraisal}

Listan nedan inleds med argument som anförs för critical appraisal. Ibland anges de i litteraturen explicit i förhållande till riktlinjemodellen, ibland inte. Somliga contraargument mot proargumenten redovisas också samtidigt i de fall contraargumenten är särskilt uppenbara.

Ortodoxiargumentet går ut på att framhålla "det ursprungliga" hos critical appraisal. Argumentet förekommer ofta när riktlinjemodellen kritiseras i termer av att den "ligger för långt ifrån" idéerna hos Sackett och hans medförfattare. Dock, att något är mer "ursprungligt" eller tidigt gör det naturligtvis inte gott. Argumentet är svagt som proargument för critical appraisal och likaså som contraargument mot riktlinjemodellen. En välvillig tolkning och en tolkning som säkerligen är mer i linje med skribenternas intentioner, är att riktlinjemodellens komponenter skiljer sig på ett negativt sätt från de komponenter som critical appraisal innehåller och det är någonting annat. Jag kommer därför att bortse ifrån ortodoxiargumentet i den fortsatta texten.

Det professionella auktoritetsargumentet tar fasta på att den professionelle praktikern inte ska förlita sig på vissa typer av auktoriteter eller på skäl som har med viss auktoritet att göra. Traditionsskäl ("så här har vi alltid gjort"), popularitetsskäl ("den här metoden arbetar många enligt"), personskäl ("X säger att vi ska arbeta på detta sätt") etc. är alla skäl som förtjänar att ifrågasättas och genom den process (critical appraisal) som praktikern genomför ges den professionelles auktoritet rättmätigt utrymme. Konsensus eller anekdotisk erfarenhet är inte heller de tillräckligt goda skäl för att arbeta på ett visst sätt (Gambrill, 2006). ${ }^{7}$

Brukarargumentet. Critical appraisal tar stor hänsyn till brukaren och den hänsy-

7 Se också Svanevie (2011) om erfarenhetsbaserad kultur, auktoritetsbaserad kultur och opinionsbaserad kultur. 
nen är en integrerad del av själva processen. För att driva argumentet hänvisas till versionen av Sackett och medförfattare från 2000, där brukarens biologiska konstitution, värderingar och omständigheter ingår som del i steg 4 . Men brukarargumentet kan också ta sig uttryck i att man hänvisar till etiska riktlinjer för verksamma inom socialt arbete, där hänsyn till brukarens perspektiv eller brukarens delaktighet och inflytande framhålls. ${ }^{8}$ Det senare kan dock utgöra argument även för riktlinjemodellen, eftersom brukarens preferenser och delaktighet utgör en del av EBP oavsett modell. Om brukarargumentet ska kunna anföras för critical appraisal gentemot riktlinjemodellen behövs alltså en argumentation (eller empiri) som visar att större hänsyn (på goda grunder) tas till brukarens preferenser etc. i critical appraisal.

Motivationsargumentet. Critical appraisal fungerar motiverande i det att praktikern har stor handlingsfrihet (större handlingsutrymme än vad som är fallet i riktlinjemodellen) och själv genomför de olika momenten i processen. Det är ett argument som utgår ifrån ett antagande om vår psykologi: att uppleva handlingsfrihet genom att utföra processen själv tänks vara motiverande. Dock, att erfara handlingsfrihet måste inte med nödvändighet fungera motiverande, det kan även upplevas belastande och tröttande att ensam ansvara för critical appraisal-processens hela genomförande.

Det kanske oftast framförda argumentet mot critical appraisal med avseende på EBP inom socialtjänst är "det orealistiska argumentet". Argumentet kan vidare delas upp i olika delar beroende på vad som hålls för att vara orealistiskt:

Critical appraisal-processen är tidsödande och i kraft av det inte ett realistiskt alternativ för socialarbetaren.

Critical appraisal kräver kompetens av ett visst slag, till exempel för att värdera sammanställningar av forskning och är i kraft av det inte ett realistiskt alternativ då praktikern inte i tillräckligt hög grad har denna kompetens.

Critical appraisal är inte realistisk då kunskap inte är entydig. Vetenskapliga studier kan uppvisa motsägelsefulla tendenser och/eller sammantaget inte utgöra någon reell vägledning för praktikern. Några ytterligare exempel på att vägledning uteblir är att relevant forskning om insatser inte finns över huvud taget eller att den befintliga forskningen inte kan uppvisa signifikanta skillnader mellan olika utvärderade arbetssätt eller metoder. De olika formerna av argumentet (att kunskap är mångtydig, obefintlig, otillräcklig eller inte utslagsgivande) kan dock träffa även riktlinjemodellen och kan inte i sig utgöra argument mot critical appraisal och endast critical appraisal.

8 Se Akademikerförbundet SSR:s etiska kod för ett svenskt exempel: "Om det finns en välgrundad evidens - genom forskning och beprövad erfarenhet - för en viss åtgärd i en viss situation bör denna åtgärd väljas. Det är därför ett etiskt krav att socialt arbete i så stor utsträckning som möjligt är en evidensbaserad praktik. I vissa situationer kan det dock vara svårt att bedöma vilken åtgärd som kan stödjas med bäst evidens. Dessutom måste alltid klientens perspektiv och önskemål vägas in" (Akademikerförbundet SSR, 2015, s. 5). Det de etiska riktlinjerna stödjer här är dock inte critical appraisal i sig, utan snarare EBP i allmänhet. 
Critical appraisal används inte av praktiker och utgör därför inte ett realistiskt förslag. Argumentet används dock också mot riktlinjemodellen, i form av det mer specifika påståendet att riktlinjer sällan används av praktiker. Båda påståendena måste beläggas empiriskt. För båda gäller också att även om modellerna inte används så utgör det inte ett gott argument mot att de borde användas, detta då icke-användandet kan vara motiverat av skäl som vi inte håller för goda. Om det kan beläggas att ingen av modellerna används eller används i ringa utsträckning så blir det således viktigt att undersöka varför; det kan finnas olika skäl för att critical appraisal och/eller riktlinjemodellen inte anammats av praktiker som är väl värda att uppmärksamma.

Det blir i det här sammanhanget lämpligt att ta upp det som skulle kunna benämnas implementeringsproblemet. ${ }^{9}$ Forskare har uppmärksammat hur EBP delvis tagit sig uttryck i hur praktiker talar om verksamheten (t.ex. som ett legitimerande tal), men däremot inte lika mycket i själva sätten att arbeta (Avby, Nilsen \& Abrandt Dahlgren, 2014). Vi kan tänka oss flera olika orsaker till det: att inte tillräckligt med stöd ges från nationellt, regionalt och/eller lokalt håll för att arbeta med EBP; att inte tillräckligt med forskning finns för att kunna arbeta med EBP; att kunskap saknas kring hur EBP ska iscensättas; att motivation för att arbeta med EBP saknas; att man tänker sig att det är critical appraisal-modellen som ska tillämpas och att denna betraktas som alltför krävande att arbeta utifrån etc. I delrapporten Utvärdering av en samlad styrning med kunskap för hälso- och sjukvård och socialtjänst konstaterar Statskontoret att"en effektiv kunskapsstyrning ska innebära ett verkligt stöd i arbetet med evidensbaserad praktik. Något sådant stöd får socialtjänsten för närvarande inte" (Statskontoret, 2016, s. 40).

\section{Argument för och emot riktlinjemodellen}

Listan nedan inleds med argument som anförs för riktlinjemodellen. De beskrivs i litteraturen ibland explicit i förhållande till critical appraisal, ibland inte. Liksom i avsnittet med argument för och emot critical appraisal redovisas vissa contraargument mot proargumenten samtidigt.

Tidsargumentet. Riktlinjemodellen innebär att praktikern kan använda sig av riktlinjer baserade på forskning och kritiska bedömningar av forskning gjorda av andra. I kraft av det minskas tidsåtgången för att genomföra processen.

Kompetensargumentet. Vetenskaplig expertis har bedömt evidensen som ligger till grund för riktlinjer och rekommendationer och i kraft av detta äger riktlinjerna en viss tillförlitlighet. Detsamma gäller bedömning av frånvaro av evidens eller otillräcklig evidens. I samband med det argumentet bör "vetenskaplig expertis" specificeras

9 Det ska inte förstås som endast ett problem, utan snarare som ett kluster av problem som rör frågor om hur implementering ska förstås och vilka möjligheter respektive hinder som finns för implementeringar. 
med avseende på $i$ vad expertisen består. SBU betonar detta vad gäller vilka som utvärderar på deras uppdrag: "Utvärderingen görs av experter inom ett ämnesområde med stöd från SBU:s kansli. Detta skiljer SBU från många andra organisationer som tar fram systematiska översikter och medicinska utvärderingar. Ofta sammanställs deras rapporter av experter på själva granskningsmetodiken och de har liten möjlighet att bedöma vilken klinisk relevans en metod har." (SBU, 2014, s. 10).

Likvärdighetsargumentet. Samma riktlinjer och rekommendationer ges till alla som arbetar inom socialtjänsten. Om alla också följer dem i sina bedömningar och i sitt arbete med brukare är det mer troligt att insatsers kvalitet kan bli likvärdiga.

Preferensargumentet. Praktiker önskar få riktlinjer och rekommendationer som hjälp i deras arbete. Det påståendet måste beläggas empiriskt (och återkommande, då preferenserna kan ändras över tid). Och, givet att det kan beläggas, så måste frågorna "i vilken utsträckning?" och "varför?" ställas. Skälen till det senare kan vara flera, såsom att kunskap inte finns om andra alternativ att bedriva EBP på eller att tillräckligt stöd för att lära sig andra sätt att arbeta på med evidens saknas. Det kan också tänkas att en vana vid att få riktlinjer och rekommendationer formar praktikernas preferenser på så vis att de även fortsättningsvis önskar sig det.

Argument mot riktlinjemodellen, som framförs i litteraturen, är bland annat:

Det icke-ortodoxa argumentet. Eftersom argumentet endast är ortodoxiargumentets motsats, behandlas det inte vidare. Det vill säga, det faktum att riktlinjemodellen inte är den "ursprungliga" eller tidigaste modellen för EBP utgör inte ett gott motargument mot den.

Selektionsargumentet. Argumentet går ut på att ifrågasätta giltigheten hos modellen genom att ta fasta på frågan om vad som räknas som evidens eller relevant kunskap vid sammanställning av forskning (jämför med the definition of evidence challenge hos Upshur \& Tracy, 2004). Skäl för att frågan uppstår kan relateras till användningen av olika evidensgraderingssystem. Forskare har noterat förekomsten av olika evidensgraderingssystem (Gambrill, 2006) som uppvisar olika evidenshierarkier och därutöver kan även ett visst systems interna hierarki ifrågasättas. ${ }^{10}$ Ett exempel på det senare är ifrågasättandet av randomiserade kontrollerade studier (RCT) som ägande mest evidensstyrka vad gäller arbetssätt och metoder i insatser inom socialtjänstens område.

Paternalismargumentet. Det som här benämns paternalismargumentet ska förstås som att staten (myndigheter) och/eller forskare agerar paternalistiskt i förhållande till socialtjänstens praktiker genom riktlinjer och rekommendationer. Gambrill framställer det på följande vis:

Paternalism is usually discussed in the helping professions as being imposed by

10 Evidensgraderingssystemet GRADE utvecklades mot just denna bakgrund av flera olika system och används nu av WHO, Cochrane med flera, förutom av Socialstyrelsen och SBU. Se SBU, 2014, s. 141. 
helpers on clients, doing things for the clients' good that clients may not choose if fully informed. Paternalism is also robust on the part of administrators and researchers if we base our conclusions on descriptions of EBP that promote a topdown approach. (Gambrill, 2006, s. 354)

Flera frågor blir här aktuella, varav jag väljer två för kort diskussion. Den första frågan gäller huruvida de svenska myndigheterna i arbetet med att försöka främja en EBP inom socialtjänsten gjort det på ett sätt som kan beskrivas som en (orättfärdig) topdown-approach. Frågan lär gissningsvis besvaras med ett ja av vissa delar av professionen och flera forskare inom socialt arbete. Bergmark och Lundström skriver: "I svenskt socialt arbete har detta program knappast drivits fram av professionen själv eller av forskare i socialt arbete. I stället är det framför allt representanter inom centralbyråkratin som introducerat företeelsen och drivit på utvecklingen” (Bergmark \& Lundström, 2011, s. 173; Björk, 2016). Och Statskontoret konstaterar att det är nödvändigt att myndigheternas arbete med kunskapsstyrning förändras för att kunna verka stödjande: "[d]et fordras ett perspektivskifte från myndigheterna som ger professionerna mer utrymme. Ett så kallat uppifrån-ner-perspektiv ska bytas mot dialog" (Statskontoret, 2016, s. 8).

Den andra frågan gäller huruvida myndigheterna, i sin top-down-approach, också agerat paternalistiskt gentemot praktikerna. I det avseendet räcker inte Gambrills förståelse av paternalism, eftersom den utesluter det skäl (som den utövande parten motiverar sitt ingripande med) som brukar krävas för att något på goda grunder ska betraktas som paternalistiskt. Dworkin föreslår följande:

I suggest the following conditions as an analysis of $X$ acts paternalistically towards $Y$ by doing (omitting) Z:

1. $Z$ (or its omission) interferes with the liberty or autonomy of $Y$.

2. $X$ does so without the consent of $Y$.

3. $X$ does so only because $X$ believes $Z$ will improve the welfare of $Y$ (where this includes preventing his welfare from diminishing), or in some way promote the interests, values, or good of Y. (Stanford Encyclopedia of Philosophy, ämnesordet paternalism)

Medan en top-down-approach alltså skulle kunna argumenteras ha varit för handen vad gäller de svenska myndigheternas $(X)$ arbete med att försöka främja en EBP inom socialtjänsten (Z) betyder inte det att den därmed också varit paternalistisk i förhållande till praktikerna $(\mathrm{Y})$, detta då villkor 3 ovan saknas i relation till praktikerna $(\mathrm{Y})$.

För att inte begreppsförvirring ska uppstå borde "paternalismargumentet" i stället formuleras som ett argument som handlar om orättmätig top-down-hållning från 
myndigheternas sida. All top-down-hållning torde medföra en inblandning i praktikers och professioners handlingsutrymme och vilka kännetecken som gör en viss top-down-hållning orättmätig i förhållande till en viss profession behöver utredas. När Statskontoret påpekar att ett perspektivskifte från myndigheternas sida är nödvändigt för att ge professionerna mer utrymme går det att tolka som att det tidigare top-down-arbetet till viss del anses ha skett på ett orättmätigt vis.

Standardiseringsargumentet. Det här argumentet går ut på att riktlinjemodellen innebär ett standardiserande eller "manualbaserande" som inte lämpar sig för socialtjänstens verksamhet. Standardisering av insatser kan betyda att utrymmet minskar för brukarens möjligheter till inflytande och delaktighet, dock kan argumentet även riktas mot critical appraisal. Björk visar exempelvis att critical appraisal-processens standardiserade form inte passar för "clients with unstable motivation and sometimes chaotic lives" (Björk, 2016, s. 63). ${ }^{11}$

Det sista argumentet mot riktlinjemodellen som här tas upp, är att den inte bidrar med tydliga riktlinjer. Argumentet fungerar troligen inte mot riktlinjemodeller i sig utan gäller en viss iscensättning, det vill säga i vårt sammanhang: "iscensättandet av riktlinjemodellen i Sverige". Att exempel på riktlinjemodeller inte har tydliga riktlinjer betyder inte att de inte skulle kunna ha det.

Argumentet om otydlighet är intressant också ur ett annat perspektiv: invändningar mot riktlinjemodeller tar sig ofta uttryck i att de är alltför styrande och begränsar de professionella i deras yrkesutövande. Det vore då inte otroligt att tänka sig att tydligare riktlinjer än mer begränsar eftersom mer specificerade anvisningar ges som minskar tolknings- och handlingsutrymmet ytterligare.

\section{Praktikerns dilemma}

Givet argumenten ovan för respektive emot de två modellerna blir följande fråga aktuell: vad bör då praktikern göra? Låt säga att en hypotetisk praktiker står inför imperativet (från myndigheter, avtal och ledningen på den lokala arbetsplatsen): "Arbeta enligt EBP". Vår praktiker känner till både argument mot critical appraisal och argument mot riktlinjemodellen med avseende på vem som bör söka efter, sammanställa och utföra värdering av evidens och håller därtill med om att invändningarna mot båda modellerna i detta avseende kan vara rimliga. ${ }^{12}$

Det första påstående som praktikern håller med om är att om hen ska söka efter, sammanställa och värdera evidens själv på den lokala nivån så finns risken att det

11 Björk nyanserar också påståendet att standardisering inte lämpar sig för socialtjänstens verksamhet genom att peka på olika typer och grader av standardisering och standardiseringsprocesser, se Björk, 2016, s. 64.

12 Det behöver naturligtvis en praktiker inte göra. Argumentens premisser kan såväl omfattas som förkastas. 
leder till bristfällig (t.ex. på grund av tidsbrist) eller tvivelaktig (t.ex. på grund av kompetensbrist) kunskap. Vi vet också att förutsättningarna för praktikern att ägna sig åt steg 2 och steg 3 i processen inte heller är gynnsamma, eftersom universitetsoch högskoledatabaser inte är tillgängliga för dem som inte är anställda eller studenter vid ett lärosäte. Problemet med de anställdas förutsättningar för att kunna ta del av aktuell forskning har uppmärksammats tidigt och i SOU 2008:18 ägnas avsnitt 8.3.1 åt just frågan om tillgång till forskning. ${ }^{13}$

Det andra påstående som praktikern håller med om är att om hen inte ska värdera evidens själv utan förlita sig på riktlinjer så finns risken att det leder till en tveksam kunskapsgrund, eftersom användandet av riktlinjer och rekommendationer kan göra att praktikern inte gör tillräckligt bruk av sin professionella kompetens och sitt kritiska tänkande. ${ }^{14}$ Praktikern är här ställd inför två möjliga alternativ med avseende på sökande av evidens, sammanställning och värdering av den och båda alternativen kan leda till oönskade konsekvenser.

Den här hypotetiska situationen är dock troligen mindre intressant än den verklighet som möter praktiker vad gäller imperativet "Arbeta enligt EBP". Som exempel kan vi ta kompetensutveckling i EBP. Sådan kan ges till socialarbetare utifrån critical appraisal som modell med samtliga steg i critical appraisal-processen presenterade samtidigt som critical appraisal i sin helhet av myndigheter och flera forskare inte hålls som realistisk för praktikern att genomföra. Om det då som en lösning införs fler inslag av riktlinjemodell som rekommenderat arbetssätt kan praktikern i stället bli omtalad som reducerad till en anpassningsbar "evidensanvändare". Poängen här kan beskrivas som att en (mindre) dimension av de omtalade implementeringssvårigheterna av EBP också har med motsägelsefullhet att göra: det budskap som sammantaget från olika aktörer förmedlas till de verksamma inom socialtjänsten blir både svårtolkat och svårt att översätta till praktisk verklighet.

\section{Från praktikerns dilemma till praktikernas möjligheter}

Givet praktikerns dilemma uppstår flera möjliga förhållningssätt. Ett är att se det som uttryck för en konflikt mellan forskare, myndigheter och profession och där det enda möjliga är att var och en av aktörerna "arbetar på som vanligt". Ett annat sätt är att ställa frågan om vi av motargumenten mot de två EBP-modellerna kan lära oss något. Går det att utveckla andra sätt att organisera EBP-arbetet på och går det att iden-

13 "Utvecklingen av en evidensbaserad praktik ställer stora krav [...]. Det förutsätter att de anställda har möjlighet att ta del av den tillgängliga kunskap som är relevant för dem i deras arbete och att det finns utrymme att söka den kunskap man är i behov av" (SOU 2008:18, s. 83).

14 Evidensanvändare, utförare av givna procedurer och genomförare är exempel på beteckningar som återfinns i litteraturen. 
tifiera några önskvärda karakteristika hos sådana andra versioner som skulle kunna motiveras?

Forskning om och förslag på hur EBP-arbetet bör organiseras har undersökts med avseende på såväl olika fält (främst den medicinska praktiken men även socialtjänstens praktik) som olika nivåer (nationell, regional och lokal). I SKL:s rapport om kunskapscentra presenteras ett urval nationella och regionala kunskapscentra där "[u]tgångspunkten har varit om det finns processer och aktiviteter som [...] stödjer socialtjänstens verksamheter i hela landet att använda och utveckla bästa tillgängliga kunskap i arbetet för brukarens bästa" (Olson, 2013). Flera av de intervjuade regionala plattformsledarna framför enligt författaren att ett nationellt kunskapscentrum inte får vara för litet "på grund av sårbarheten och att kontakterna och dialogen med användarna och övriga intressenter då inte kan upprätthållas på rimlig nivå” (Olson, 2013, s. 11). Uppfattningen att ett nationellt kunskapscentrum inte heller får vara för "smalt" framförs också av de intervjuade (Olson, 2013, s. 11).

SKL:s rapport behandlar nationella och regionala kunskapscentra, men ställer också frågan om hur kunskap ska anpassas till de lokala förutsättningarna och om kommuner kan härbärgera metodcentra: "[d]en stora fördelen med att ha ett metodcentrum i kommunen är att den är en del av verksamheten, vilket ger impulser $\mathrm{i}$ utvecklings- och implementeringsarbetets alla faser. Det ger också en annan riktning på den traditionella top down-implementeringen av ny kunskap och nya metoder" (Olson 2013, s. 34).

Den lokala nivå som är aktuell för hur en viss verksamhets EBP-arbete bör organiseras är beroende av hur den nationella och regionala organiseringen ser ut (t.ex. om det finns ett adekvat stöd från dem eller inte), och därtill finns lokala förutsättningar som de lokala förslagen behöver förhålla sig till.

Vad för slags verksamhet inom en viss kommuns socialtjänst det rör sig om är också viktigt. Hur organiseringen bör se ut beror på om det exempelvis är myndigheten eller olika utförare som avses eller relationerna mellan dem. De utmaningar som en kommunal beställar-utförar-modell står inför vad gäller EBP-arbetet kan vara stora. Ta som exempel handläggning av - och beslut i - ärende på ett ställe, beställning av utförande från ett andra ställe och utförande av insats på ett tredje. ${ }^{15}$ Därtill är det inte ovanligt att en brukare omfattas av flera olika beslut och flera olika utföranden, ibland från såväl kommunal utförare som privat. Ett gott EBP-arbete för brukarens bästa i en dylik komplex organisation torde kräva ett långtgående samarbete mellan de olika enheterna. Till Statskontorets påpekande att "ett välfungerande samspel

15 I en sådan här modell blir alltså frågan om en praktiker ska eller inte ska söka, sammanställa och värdera evidens själv svår att ställa, detta då den kommunala organiseringen delat upp praktiker och deras arbetsuppgifter med avseende på samma brukare på olika ställen. 
mellan nationell, regional och lokal nivå" är nödvändigt för "att brukare ska få insatser som vilar på bästa tillgängliga kunskap" vill jag alltså lägga till ett välfungerande lokalt samspel mellan de olika delar som utgör en kommuns socialtjänst (Statskontoret, 2014 , s. 9). Frågan om hur socialtjänsten är organiserad inom en viss kommun är av vikt för de förslag på organisering av EBP-arbete som läggs fram och vi kan även vända på frågan: givet att socialtjänsten med hjälp av en evidensbaserad praktik ska verka för brukarnas bästa, hur bör då en kommuns socialtjänst organiseras?

Därutöver finns de tjänster som socialtjänsten tillhandahåller som inte föregås av myndighetsbeslut. Där kan en brukare vända sig direkt till en utförare och således äger EBP-arbetet då rum där eller inleds där, i de fall ett myndighetsbeslut fattas senare.

Förslag på lokal organisering av "mellanvarianter" av EBP-arbete har framförts av forskare från både den medicinska praktiken och från socialt arbete. ${ }^{16}$ Bergmark, Bergmark och Lundström har presenterat ett alternativ till critical appraisal och riktlinjemodellen som kan genomföras genom att avbyråkratisera iscensättningen av EBP, en vetenskaplig kritisk pluralism samt att formulera "nya perspektiv på praktikens karaktär och möjligheterna till ett inflöde av vetenskaplig kunskap" (Bergmark, Bergmark \& Lundström, 2011, s. 157). Författarna tror också "att det behövs särskilt utsedda personer för att driva evidensfrågor på lokal nivå" och att de bland annat ska ha "ett tydligt ansvar [för] att hålla sig uppdaterade om kunskapsläget [...] och att hålla kontakt med forskare" (Bergmark, Bergmark \& Lundström, 2011, s. 168f.).

I en kort text av Gray som behandlar den medicinska praktiken nämns funktionen "the chief knowledge officer" som ansvarar för att exempelvis hålla organisationen uppdaterad kring nya kunskapsöversikter och riktlinjer och även för att information till patienter är "evidence based and comprehensible" (Gray, 1998, s. 832). I ett senare verk beskrivs uppgifterna mer utförligt med avseende på evidens (modeling, searching, appraising, storing, using) och där betonas också vikten av att organisationens struktur främjar (EBP)arbetet, bland annat genom ett "evidenscenter" med exempelvis tillgång till databaser som en resurs (Gray, 2001).

Björk betonar vikten av organisationen som utgångspunkt när EBP-arbetet ska utvecklas och frågar sig om critical appraisal ska bedrivas av praktikern i varje fall: "A more realistic alternative would be to give at least one social worker or manager in a social work agency the task of critically appraising research evidence in relation to the clients' problems." Det föreslås gälla särskilt svåra eller ovanliga fall "where universal guidelines fall short" (Björk, 2016, s. 69).

Av de argument som framförts emot modellen critical appraisal och riktlinje-

16 Ordvalet mellanvarianter låter antyda att jag ser på modellen critical appraisal och riktlinjemodellen som att de skiljer sig åt i grad och inte i art. Den hållningen kan man mycket väl invända mot. 
modellen tar jag här fasta på följande: (1) "det orealistiska argumentet" (här med avseende på att critical appraisal kräver för mycket tid och kompetens; (2) top-downargumentet (här betyder det top-down-hållningen som motargument mot riktlinjemodellen) och (3) selektionsargumentet (här med avseende på den kritiska frågan mot riktlinjemodeller om vilken forskning som sammanställs och utgör grund för rekommendationer och riktlinjer).

Skälen för detta urval är att alternativen (1) och (2) framstår som förhållandevis centrala, både i forskningen och i debatten. Riktlinjemodellen kan också betraktas som ett svar på just "det orealistiska argumentet" mot critical appraisal. Top-downargumentet är i sin tur en kritik av det sätt som riktlinjemodellen svarar på "det orealistiska argumentet". Skälen för valet av alternativ (3) härrör från forskning som framför behovet av "en kritisk pluralism" (se Bergmark, Bergmark \& Lundström ovan, 2011, s. 157). Alternativ (3) kan också ha en anknytning till (2), om kritiken mot den utvalda forskningen som en riktlinjemodell presenterar baserar sig på top-down-argument.

Går det nu att identifiera några önskvärda karakteristika hos andra versioner av EBP-organisering mot bakgrund av forskarnas förslag ovan samt de utvalda motargumenten? Förslagen nedan är tentativa, men kan förhoppningsvis bana väg för en fortsatt diskussion. ${ }^{17}$

Mot bakgrund av "det orealistiska argumentet" framförs förslag som ligger i linje med vad forskarna ovan presenterat. Oavsett om det benämns lokalt evidenscenter, kunskapscentrum, utvecklingsenhet eller något annat, så är stabilitet och kontinuitet goda kännetecken hos ett sådant. Kontra Gray bör dock EBP-arbetet organiseras på ett sådant sätt att inte endast en person har ansvaret för att vara "evidence-based chief administrator", detta då verksamheten riskerar att bli sårbar. Risken rör alltså inte endast nationella kunskapscentra utan också (och troligen i än högre grad) lokala sådana. Tillgång till, information om, värdering av och diskussion kring ny forskning ska inte riskera att upphöra eller drabbas av långa avbrott på grund av att en person slutar sin anställning eller blir sjuk och fler än en person bör alltså ha tid avsatt för funktionen och kontinuerlig utbildning i det som krävs för att kunna upprätthålla den. Vilka personer som bör ingå i enheten, beror på hur socialtjänsten är organiserad i den kommun det gäller men också hur praktikerna själva tolkar kännetecknet tillräcklig närhet (se nedan).

Mot bakgrund av top-down-argumentet föreslås kännetecknet tillräcklig närhet. Men oavsett om vi beaktar förslag som rör den nationella, regionala eller den lokala

17 De föreslagna kännetecknen ska inte förstås som alternativ till de båda EBP-modellerna och inte heller beskriver de hur ett implementeringsarbete ska se ut. I linje med min förståelse av skillnaden mellan critical appraisal och riktlinjemodellen som en fråga om grad och inte art, är förslagen snarast att beteckna som en fråga om "hur graderingen bör ställas in" med avseende på några aspekter. 
nivån, uppstår bedömningsfrågor som gäller både en praktisk funktion och en "symbolisk" funktion: hur "nära praktiken" behöver dessa enheter eller aktörer vara för att den bokstavliga men också upplevda nåbarheten och tillgängligheten ska vara god (mellan lokal, regional och nationell nivå men också mellan olika lokala enheter)? Och hur nära praktiken behöver enheter eller aktörer vara för att erhålla legitimitet, det vill säga inte upplevas som top-down i en negativ bemärkelse från praktiker (och forskare?)? En grundläggande fråga här blir när en top-down-approach är eller upplevs som orättfärdig och vad som gör den orättfärdig $i$ ett visst sammanhang. Kännetecknet tillräcklig närhet ger i sig inga generella svar utan bedömningen av om kännetecknet är närvarande eller inte föreslås att de gör som berörs. Vi kan här tänka oss flera olika förslag som för olika professionella kan vara olika viktiga: att "kunskapscentret" befinner sig fysiskt nära, att det sätt som centret bedriver sitt arbete på upplevs nära, att praktiker får möjlighet att vara delaktiga, att praktiker har reellt inflytande, att centret drivs av praktiker etc.

Mot bakgrund av selektionsargumentet föreslås kännetecknet mångdisciplinaritet. Det berör endast en del av de frågor som kan ställas kring sammanställningar av forskning som utgångspunkt för rekommendationer och riktlinjer men är likväl värt att framhålla. Olika professioner samarbetar ofta i team med insatser för brukare och de akademiska discipliner som kan bidra med kunskap i form av forskning är alltså flera. Ett evidenscenter eller kunskapscenter bör därför ha en omvärldsbevakning och vetenskaplig diskussion som innefattar en förhållandevis "bred blick", inte bara med avseende på olika typer av forskning inom en viss disciplin utan också med avseende på olika discipliner. Forskning om såväl olika arbetssätt inom socialtjänsten som forskning om brukares delaktighet och inflytande kan exempelvis vara av vikt.

\section{Referenser}

Akademikerförbundet SSR (2015) Etik $i$ socialt arbete: Etisk kod för socialarbetare. Stockholm: Akademikerförbundet SSR. Tillgänglig: https://akademssr.se/sites/default/files/files/etik_och_ socialt_arbete.pdf

Avby, G., Nilsen, P. \& Abrandt Dahlgren, M. (2014) Ways of understanding evidence-based practice in social work: A qualitative study. British Journal of Social Work, 44(6): 1366-1383.

Bergmark, A., Bergmark, Å. \& Lundström, T. (2011) Evidensbaserat socialt arbete: Teori, kritik, praktik. Stockholm: Natur \& Kultur.

Bergmark, A. \& Lundström, T. (2011) Evidensbaserad praktik i svenskt socialt arbete: Om ett programs mottagande, förändring och möjligheter i en ny omgivning. I: I. Bohlin \& M. Sager (red.), Evidensens många ansikten: Evidensbaserad praktik i praktiken (s. 163-182). Lund: Arkiv förlag.

Björk, A. (2016) Evidence-based practice behind the scenes: How evidence in social work is used and produced. Akademisk avhandling. Stockholm Studies in Social Work, SSSW32. Stockholm: Stockholms universitet.

Dahlberg, M. \& Vedung, E. (2001) Demokrati och brukarutvärdering. Lund: Studentlitteratur. 


\section{Socialvetenskaplig tidskrift 2017:3-4}

Denvall, V. \& Johansson, K. (2012) Kejsarens nya kläder: Implementering av evidensbaserad praktik i socialt arbete. Socialvetenskaplig tidskrift, 19(1): 26-45.

Dir. 2007:91, Kommittédirektiv: Nya former för stöd till kunskapsutvecklingen inom socialtjänsten. I: SOU 2008:18. Evidensbaserad praktik inom socialtjänsten: Till nytta för brukaren. Stockholm: Fritzes.

Gambrill, E. (2006) Evidence-based practice and policy: Choices ahead. Research on Social Work Practice, 16(3): 338-357.

Gibbs, L. \& Gambrill, E. (2002) Evidence-based practice: Counterarguments to objections. Research on Social Work Practice, 12(3): 452-476.

Gray, J.A.M. (1998) Where is the chief knowledge officer? British Medical Journal, 317(7162): 832.

Gray J.A.M. (2001) Evidence-based healthcare: How to make health policy and management decisions. (2 uppl.). New York: Churchill Livingstone.

Liljegren, A. \& Parding, K. (2010) Ändrad styrning av välfärdsprofessioner: Exemplet evidensbasering i socialt arbete. Socialvetenskaplig tidskrift, 17(3-4): 270-288.

Martinell Barfoed, E. (2014) Standardiserad interaktion: En utmaning för socialt arbete. Socialvetenskaplig tidskrift, 21(1): 4-23.

Munthe, C., Nykänen, P. \& Sandman, L. (2015) Delat beslutsfattande och evidensbaserad praktik inom socialtjänsten: Mål, begrepp och etik för utformning och implementering. Philosophical Communications. Web Series, ISSN 1652-0459; nr 62. Göteborg: University of Gothenburg.

Odhnoff, C. (2016) Att förstå EBP: Översättningar av idén om en evidensbaserad praktik i den svenska socialtjänsten. (Masteruppsats). Förvaltningshögskolans rapporter nummer 139. Göteborg: Förvaltningshögskolan, Göteborgs universitet. Tillgänglig: http://hdl.handle.net/2077/41795.

Olson, U.J. (2013) Nationella kunskapscentra och andra nationella/regionala kunskapskluster inom socialtjänsten. Stockholm: Sveriges Kommuner och Landsting (SKL).

Ponnert, L. \& Svensson, K. (2011) När förpackade idéer möter organisatoriska villkor. Socialvetenskaplig tidskrift, 18(3): 168-185.

Rexvid, D. (2016) Professionsutövning och kunskapsstyrning: En jämförelse av socialarbetares och allmänläkares klientarbete. Akademisk avhandling. Umeå: Umeå universitet, Institutionen för socialt arbete.

Rosen, A. \& Proctor, E. (2003) Developing practice guidelines for social work intervention: Issues, methods and research agenda. New York: Columbia University Press.

Sackett, D.L., Richardson, W.S., Rosenberg, W. \& Haynes, R.B. (1997) Evidence-based medicine: How to practice and teach EBM. New York: Churchill Livingstone.

Sackett, D.L., Straus, S.E., Richardson, W.S., Rosenberg, W. \& Haynes, R.B. (2000) Evidence-based medicine: How to practice and teach EBM (2 uppl.). New York: Churchill Livingstone.

SBU (2014) Utvärdering av metoder $i$ hälso- och sjukvården: En handbok (2 uppl.) Stockholm: Statens beredning för medicinsk utvärdering (SBU).

Socialdepartementet (2010) Plattform för arbetet med att utvärdera en evidensbaserad praktik $i$ Socialtjänsten: En överenskommelse mellan staten och Sveriges Kommuner och Landsting. S2009/4028ST, bilaga till protokoll vid regeringssammanträde 2010-06-17 nr III:8. Stockholm: Regeringskansliet.

Socialdepartementet (2011) Stöd till en evidensbaserad praktik för god kvalitet inom socialtjänstens område: Överenskommelse för 2011 mellan staten och Sveriges Kommuner och landsting. Stockholm: Socialdepartementet.

Socialdepartementet (2012) Stöd till en evidensbaserad praktik för god kvalitet inom socialtjänstens område: Överenskommelse för 2012 mellan staten och Sveriges Kommuner och landsting. 
Stockholm: Socialdepartementet.

Socialdepartementet (2013) Stöd till en evidensbaserad praktik för god kvalitet inom socialtjänstens område: Överenskommelse för 2013 mellan staten och Sveriges Kommuner och landsting. Stockholm: Socialdepartementet.

Socialdepartementet (2014) Stöd till en evidensbaserad praktik för god kvalitet inom socialtjänstens område: Överenskommelse för 2014 mellan staten och Sveriges Kommuner och landsting. Stockholm: Socialdepartementet.

Socialdepartementet (2015) Stöd till en evidensbaserad praktik för god kvalitet inom socialtjänstens område: Överenskommelse för 2015 mellan staten och Sveriges Kommuner och landsting. Stockholm: Socialdepartementet.

Socialdepartementet (2016) Stöd till en evidensbaserad praktik för god kvalitet inom socialtjänstens område: Överenskommelse för 2016 mellan staten och Sveriges Kommuner och landsting. Stockholm: Socialdepartementet.

Socialstyrelsen (2012a) Att skapa en grund för evidensbaserad praktik: En guide för ledningen i vård och omsorg. Stockholm: Socialstyrelsen.

Socialstyrelsen (2012b) Om evidensbaserad praktik. Stockholm: Socialstyrelsen.

Socialstyrelsen (2013) Resultat av remiss för begreppet brukaret (sic!). Stockholm: Socialstyrelsen.

Socialstyrelsen (2017) Kunskapsguiden.se. [http://www.kunskapsguiden.se/Sidor/start.aspx. Hämtad 2017-04-12.]

SOU 2008:18. Evidensbaserad praktik inom socialtjänsten: Till nytta för brukaren. Stockholm: Fritzes.

The Stanford Encyclopedia of Philosophy (2017) Paternalism. [https://plato.stanford.edu/entries/ paternalism/. Hämtad 2017-04-12.]

Statskontoret (2014) Evidensbaserad praktik inom socialtjänsten: Utvärdering av överenskommelsen mellan regeringen och SKL. 2014:18. Stockholm: Statskontoret.

Statskontoret (2016) Utvärdering av en samlad styrning med kunskap för hälso- och sjukvård och socialtjänst: Delrapport. Stockholm: Statskontoret.

Statskontoret (2017) Webbsida: Utredningar och utvärderingar. [http://www.statskontoret.se/ var-verksamhet/utredningar-utvarderingar-och-uppfoljningar/.Hämtad 2018-01-18.]

Svanevie, K. (2011) Evidensbaserat socialt arbete: Från idé till praktik. Akademisk avhandling. Umeå: Umeå universitet, Institutionen för socialt arbete.

Upshur, R. \& Tracy, S. (2004) Legitimacy, authority, and hierarchy: Critical challenges for evidence-based medicine. Brief Treatment and Crisis Intervention, 4(3): 197-204.

Denna artikel har författats med stöd från Riksbankens Jubileumsfond. 